\title{
Yaşlı Kadınlarda Kemik Fraktürü ile Kemik Mineral Yoğunluğu İlişkisi
}

\author{
Bülent Çakmak', Ahmet Inanır²
}

\begin{abstract}
ÖZET:
Yaşlı kadınlarda kemik fraktürü ile kemik mineral yoğunluğu ilişkisi

Amaç: Bu çalışmanın amacı kemik fraktürü olan ve olmayan yaşıl kadınların kemik mineral yoğunluklarının karşılaştırılmasıdır.

Gereç ve Yöntem: Hastanemizde Ocak 2010 - Haziran 2012 tarihleri arasında kemik mineral yoğunluğu (KMY) ölçümü yapılmış 65 yaş ve üzeri kadın hastaların dosyaları retrospektif olarak demografik özellikleri ve KMY değerleri bakımından değerlendirildi. Yaş, vücut kitle indeksi (VKi), menopoz süresi, ek sistemik hastalıklar, osteoporoz varlığı ve KMY değerleri kemik fraktürü olan ve olmayan hastalar arasında karşılaştırıldı.

Bulgular: Çalışmaya alınan 102 hastanın 17'sinde (\%16.3) kemik fraktürü saptandı. Kemik fraktürü olan ve olmayan hastalar arasında yaş, VKi, menopoz süreleri ve ek sistemik hastalık varlığı açısından fark saptanmadı ( $p>0.05$ ). Benzer şekilde her iki grup arasında osteoporoz sıklığı, lomber vertebra ve femur total KMY ve T skorları açısından anlamlı fark saptandı ( $p>0.05$ ).

Sonuç: Geriatrik dönem kadınlarda kemik fraktür riski yalnızca KMY ile ilişkili olmayıp kemiğin içerik ve yapısı gibi özelliklere ve bu yaşlarda sıkça görülen düşme ile de ilişkili olabileceği akılda tutulmalıdır. Anahtar kelimeler: Kemik mineral yoğunluğu, fraktür, yaşıı kadın
\end{abstract}

\section{ABSTRACT:}

Bone mineral density and bone fracture relationship in elderly women

Objective: The aim of this study was to compare the bone mineral density in elderly women with and without bone fracture.

Material and Method: The records of the $\geq 65$ years women patients who had been performed bone mineral density (BMD) measurements in our hospital between January 2010 and June 2012 were evaluated according to their demographic features and BMD measurements retrospectively. Age, body mass index (BMI), menopause period, systemic disease, presence of osteoporosis and BMD were compared between patients with and without bone fracture.

Results: Bone fracture was determined in 17 (16.3\%) of 102 patient admitted in our study. There was no significant difference between patients with and without bone fracture for age, BMI, menopause period and systemic diseases ( $p>0.05$ ). Similarly, there was no significant difference between two groups for the presence of osteoporosis, total BMD values and T scores of lomber spine and femur (p>0.05).

Conclusion: Risk of bone fracture in geriatric women is not only associated with BMD. We should keep in mind that the risk may be associated with features such as content and structure of the bone and fall common seen in these ages.

Key words: Bone mineral density, fracture, elderly women

Ş.E.E.A.H. Tıp Bülteni 2014;48(2):91-5
'Gaziosmanpaşa Üniversitesi, Tıp Fakültesi, Kadın Hastalıkları ve Doğum Anabilim Dalı, Tokat-Türkiye

${ }^{2}$ Gaziosmanpaşa Üniversitesi, Tıp Fakültesi, Fiziksel Tıp ve Rehabilitasyon Anabilim Dalı, Tokat-Türkiye

Yazışma Adresi / Address reprint requests to: Bülent Çakmak,

Gaziosmanpaşa Üniversitesi, Tıp Fakültesi, Kadın Hastalıkları ve Doğum Anabilim Dalı, Ali Şevki Erek Yerleşkesi, 60100, Merkez,

Tokat-Türkiye

E-posta / E-mail:

drbulentcakmak@hotmail.com

Gelis tarihi / Date of receipt: 28 Ekim 2013 / October 28, 2013

Kabul tarihi / Date of acceptance: 12 Aralık 2013 / December 12, 2013

\section{GíRiş}

Osteoporoz, kemik kütlesinde azalma ve kemiğin mikro-mimari yapısında meydana gelen değişiklikler ve buna bağlı olarak kemik dokunun daha kırılgan hale gelmesi ile karakterize bir kemik hastalığıdır (1). Kemik mineral yoğunluğundaki azalma kadınlarda özellikle menopozdan sonra hızla ilerlemekte ve her yıl yaklaşık \%1 düzeyinde azalmaya devam etmekte$\operatorname{dir}(2)$.

Günümüzde ortalama insan ömrü giderek uzamakta ve bununla birlikte ileri yaş popülasyon ve beraberinde ortaya çıkan sağlık sorunları da giderek artmaktadır. Uzayan yaşam süresi ile birlikte osteoporoz dünyanın birçok bölgesinde majör halk sağlığı problemlerinden biri olarak kabul edilmektedir. 
Osteoporoz ve yol açtığı kırıklarla yaşam kalitesinin bozulması ise bu sorunların en önemlilerinden birisidir. Yaşlı popülasyonda görülen kırıklar morbidite ve mortalitede belirgin artışa neden olmaktadır. Kalça kırığı sonrası ilk yıl içerisinde mortalite oranı \%14-36 arasında değişmektedir. Bununla birlikte bir kalça kırı̆̆ı sonrası hastaların yalnızca \%33-40'ı normal yaşamlarına geri dönmekte, \%10-60'ı ise eve geri dönememektedir (3).

Günümüzde kırık riskini belirlemek için osteoporoz tanı ve takibinde, kemik mineral yoğunluğu (KMY) ölçümü esasına göre çalışan ve $K M Y^{\prime} y i$ belirlemede doğruluğu kanıtlanmış, duyarlılığı yüksek, girişimsel olmayan dual enerji X-ray absorbsiyometri (DEXA) kullanılmaktadır (4). Kemik mineral yoğunluğu kırık riskinin belirlenmesinde en önemli belirleyici faktördür (5). Bununla birlikte birçok çalışmada, kemik kırığı olanların \%50'sinden fazlasında KMY ölçümü toplum ortalamalarının içerisinde olduğu saptanmıştır $(6,7)$.

Bu çalışmanın amacı, yaşlı kadınlarda kemik kırığının kemik mineral yoğunluğu ile olan ilişkisini araştırmaktır.

\section{GEREÇ VE YÖNTEM}

Bu çalışma hastanemize Ocak 2010 - Haziran 2012 tarihleri arasında başvuran ve Fizik Tedavi Ünitesi'nde KMY ölçümü yapılmış 65 yaş ve üzeri 102 kadın hastanın dosyaları incelenerek yapılmıştır. Hasta dosyalarından hastaların yaş, VKi, menopoz süresi, sistemik hastalıkları, osteoporoz varlığı, KMY değerleri, geçirilmiş kırık öyküleri kaydedilmiştir. Elde edilen veriler fraktür öyküsü olan ve olmayan hastalar arasında karşılaştırıldı.

Hastaların KMY ölçümleri DEXA ile yapıldı. Posteroanterior lomber omurga (L1-L4) ve kalça (femur boynu, trokanterik bölge, intertrokanterik bölge, ward's üçgeni) ölçümleri yapıldı. KMY değerleri gr/ $\mathrm{cm}^{2}$ olarak ve pik genç erişkin kemik yoğunluk değerine göre belirlenen $T$ skorları ile değerlendirildi. T skoru aynı cins erişkinlerin ortalamasına göre -2.5 standart deviasyonunun altında olan KMY değerleri "osteoporoz" olarak değerlendirildi (8).

İstatistiksel karşılaştırmalarda Pearson ki-kare, Fisher kesin ki-kare, bağımsız iki örneklem t testi kullanıldı. Parametrik değişkenler ortalama \pm SD (standart sapma) ve kategorik değişkenler sayı ve yüzde (\%) ile gösterildi. P değerleri 0.05 'in altında hesaplandığında istatistiksel olarak anlamlı kabul edildi. Hesaplamalar hazır istatistiksel yazılım ile yapıldı (PAWS Statistics version 18, SPSS inc.).

\section{BULGULAR}

Çalışmaya alınan 102 geriatrik kadının yaş ortalaması 70.2 \pm 5.1 yıl idi. Hastaların 17'sinde (\%16.3) kemik fraktürü mevcut olup 85'inde (\%83.7) her hangi bir kemik fraktürü veya geçirilmiş fraktür öyküsü mevcut değildi.

Kırık olan olmayan hastaların yaş ortalaması arasında fark saptanmadı ( $p=0.082)$. İki grup arasında menopoz süresi, VKi ve ek sistemik hastalık varlığı karşılaştırıldığında aralarında istatistiksel anlamlı fark saptanmadı ( $p>0.05)$ (Tablo 1).

Osteoporoz, kırık olan 17 hastanın 6'sında (\%35.3) ve kırık olmayan 85 hastanın 26 'sında (\%30.6) saptandı. Osteoporoz sıklığı açısından iki

Tablo 1: Kemik fraktürü olan ve olmayan kadınların demografik özelliklerinin karşılaştırılması

\begin{tabular}{lccc}
\hline & $\begin{array}{c}\text { Kemik fraktürü (+) } \\
(\mathbf{n = 1 7})\end{array}$ & $\begin{array}{c}\text { Kemik fraktürü (-) } \\
(\mathbf{n = 8 5 )}\end{array}$ & p \\
\hline Yaş (yıl) & $72.9 \pm 6.9$ & $69.7 \pm 4.5$ & 0.082 \\
VKi (kg/m²) & $30.3 \pm 4.7$ & $31.1 \pm 4.6$ & 0.552 \\
Menopoz süresi (yıl) & $23.9 \pm 7.6$ & $20.5 \pm 4.4$ & 0.084 \\
Sistemik hastalık [n(\%)] & $10(58.8)$ & $49(57.6)$ & 0.929 \\
Hipertansiyon & $10(58.8)$ & $40(47.0)$ & 0.433 \\
Diabetes mellitus & $3(17.6)$ & $23(27.0)$ & 0.549 \\
Hiperlipidemi & $2(11.7)$ & $17(20.0)$ & 0.733 \\
Hipertiroidi & $1(5.8)$ & $9(10.5)$ & 0.476 \\
Artroz & $2(11.8)$ & $5(5.9)$ & 0.330 \\
\hline
\end{tabular}

VKi: Vücut kitle indeksi 
Tablo 2: Kemik fraktürü olan ve olmayan hastaların KMY sonuçlarının karşılaştırılması

\begin{tabular}{lccc} 
& $\begin{array}{c}\text { Kemik fraktürü (+) } \\
(\mathbf{n = 1 7 )}\end{array}$ & $\begin{array}{c}\text { Kemik fraktürü (-) } \\
(\mathbf{n = 8 5 )}\end{array}$ & $\mathbf{p}$ \\
\hline Osteoporoz [n(\%)] & $6(35.3)$ & $26(30.6)$ & 0.777 \\
Lomber vertebra total KMY $\left(\mathrm{gr} / \mathrm{cm}^{2}\right)$ & $0.84 \pm 0.17$ & $0.87 \pm 0.17$ & 0.487 \\
Femur total KMY $\left(\mathrm{gr} / \mathrm{cm}^{2}\right)$ & $0.84 \pm 0.15$ & $0.88 \pm 0.12$ & 0.253 \\
Lomber vertebra total T skoru & $-1.8 \pm 1.5$ & $-1.4 \pm 1.4$ & 0.384 \\
Femur total T skoru & $-0.8 \pm 1.2$ & $-0.4 \pm 0.9$ & 0.321 \\
\hline KMY: Kemik mineral yoğunluğu $\left(\mathrm{gr} / \mathrm{cm}^{2}\right)$ & & &
\end{tabular}

grup arasında istatistiksel fark saptanmadı $(p=0.777)$. Lomber vertebra total KMY ve femur total KMY iki grupta da benzer olarak bulundu ( $p>0.05)$. Kırık olan hastaların lomber vertebra total KMY $0.84 \pm 0.17$ ve femur total KMY $0.84 \pm 0.15 \mathrm{gr} / \mathrm{cm}^{2}$ iken kırık olmayan hastalarda bu değerler sırasıyla $0.87 \pm 0.17$ ve $0.88 \pm 0.12 \mathrm{gr} / \mathrm{cm}^{2}$ olarak tespit edildi. Tablo $2^{\prime}$ de de görüldüğü üzere her iki grup lomber vertebra ve femur total T skorları karşılaştırıldığında aralarında istatistiksel fark saptanmadı ( $p>0.05)$.

\section{TARTIŞMA}

Geriatrik dönemde oluşan kemik fraktürleri yaşlılar için yaşam kalitesinde büyük oranda azalmaya neden olmaktadır (9). Ayrıca kemik fraktürleri bu dönemde önemli morbidite ve mortalite nedeni olmakla birlikte; harcama maliyetleri de kritik rol oynamaktadır. Bu bağlantıda kemik fraktür oranlarının bilinmesi ve önleme çalışmaları vazgeçilmezdir. Çalışmamızda geriatrik dönem kadınlarda kemik fraktür oranı \%16.3 olarak saptanmıştır. Ülkemizde geriatrik dönem hastalarda (kadın-erkek ayırımı yapılmaksızın) kemik fraktür oranı \%7.3 - 14.3 arasında değişmektedir $(10,11)$. Keskin ve ark. geriatrik dönem kadınlarda yaptıkları araştırmada ise kemik fraktür oranını \%38 olarak tespit etmişlerdir (12). Ülkemizden yapılan başka bir çalışmada ise postmenopozal dönem kadınlarda kemik fraktür sıklığı \%31.4 olarak bulunmuştur (13). Ülkemizde geriatrik dönem kadınlarda kemik fraktür sıklığının belirlenmesi için daha fazla çalışmalara ihtiyaç olduğu bir gerçektir.

Menopoz süresi ile KMY arasında doğrudan ilişki olup KMY'da azalma erken postmenopozal dönemde daha belirgindir ve artmış kırık riski ile ilişkilidir
(14). Akdemir ve ark. cerrahi menopoz sonrası KMY'daki azalmanın postmenopozal 20. yıldan sonra değişmediğini bildirmiştir (15). Yaş, KMY'dan bağımsız olarak artmış fraktür riski ile ilişkilidir (16). Bizim çalışmamızda, fraktür saptanan ve saptanmayan hastaların yaş ortalamaları arasında istatistiksel olarak anlamlı fark bulunmamıştır. Bu konu ile ilgili bir çalışmada geriatrik kadınlarda fraktür olan ve olmayanlar arasında yaş açısından fark saptanmamıştır (12). Yine aynı çalışmada VKi ile kırık saptanma oranları arasında anlamlı fark saptanmamıştır. Bizim çalışmamızda da fraktür olan ve olmayan hastalarda VKi sırasıyla $30.3 \pm 4.7$ ve $31.1 \pm 4.6 \mathrm{~kg} / \mathrm{cm}^{2}$ olarak saptanmış olup aralarında anlamlı fark saptanmamıştır. VKi'nin yüksek olması osteoporoz riskini azaltmaktadır ve obezlerde osteoporoz ve kırık gelişimi daha az görülmektedir (17). Ancak yaşla beraber fiziksel fonksiyonlar azalmakta ve bu durum obezlerde daha belirgin olmaktadır (18). Fiziksel fonksiyon azalması düşme riskini artırmakta ve bu nedenle de obez yaşlı hastalarda kırık oranlarının obez olmayanlarla benzer olduğu düşünülmektedir.

KMY değerinin genç erişkinlerin ortalama seviyesinin en az 2.5 standart sapma altında olması osteoporozu olan kişileri belirlemede kullanılır (8). Birçok çalışma yalıız KMY ölçümünün kırık gelişecek kadınların çoğunluğu tanımlamada yeterince duyarlı olmadığını göstermektedir (19-21). Ancak bununla birlikte osteoporoz tanısını koymada halen KMY kullanılmaktadır. Yaşlı insanlarda on yıllık periodda fraktür gelişmesi aynı KMY sahip genç erişkin bireylerle karşılaştırıldığında 10 kat daha fazladır. Seksen yaşındaki bir insanın aynı KMY sahip 50 yaşındaki bir insana göre kalça kırı̆̆ı gelişmesi 5 kat daha fazladır (22). Yani KMY aynı olan tüm bireylerin kırık riskleri aynı değildir. Ayrıca kadınlardaki tüm kırık vakalarının \%50'sin- 
den fazlası T skoru -1/-2.5 arasında olan osteopenik olgularda görülmektedir ki; bu grup kadınlar DSÖ'nün kırık için riskli olarak kabul ettiği osteoporoz grubunda değildirler (23). Bizim çalışmamızda fraktür olan ve olmayan hastalarda osteoporoz oranları benzer olarak saptanmıştır ( $p=0.777)$. Aynı şekilde fraktür olanlarda KMY ortalama lomber vertebra total değeri $0.84 \pm 0.17$ ve femur total değeri $0.84 \pm 0.15 \mathrm{gr} / \mathrm{cm}^{2}$ iken bu değerler fraktür olmayanlarda sırasıyla $0.87 \pm 0.17$ ve $0.88 \pm 0.12 \mathrm{gr} / \mathrm{cm}^{2}$ olarak bulunmuştur. Gerek lomber vertebra ve femur total KMY değerleri, gerekse T skorları kırık olan ve olmayan hastalar arasında karşılaştırıldığında aralarında anlamlı fark saptanmamıştır ( $p>0.05)$. Ülkemizden yapılmış iki çalışmada da postmenopozal dönemde kemik fraktürü olan ve olmayan hastalar arasında KMY ve lomber ve femur total T skorları arasında fark bulunmadığı bildi- rilmiştir $(12,24)$. Kemik gücünü, fraktüre karşı yatkınІığı artıran bir çok faktör etkilemektedir. Kemik gücünde hem kemik matriks yapısı ve mineral içeriği gibi materyal özellikleri hem de mikro-mimari gibi yapısal özellikler önem taşımaktadır (25). Dolayısıyla geriatrik dönem hastalarda kemik fraktür riskini değerlendirirken yalnızca DEXA ile KMY ölçümleri yeterli görünmemektedir.

Sonuç olarak; postmenopozal dönemde kadınlarda görülen kalça ve femur fraktürlerinin çoğu postmenopozal osteoporoza bağlı olmakla birlikte, kemik kuvvetinde mineral içeriği, matriks yapısı ve kemiğin mikroyapısı da önemlidir. Özellikle geriatrik dönem kadınlarda kemik fraktür riskini araştırırken yalnızca KMY kullanmak yerine diğer risk faktörlerini de (kemik içeriği, yapısı ve düşme riski gibi) göz önünde bulundurmak gerektiği kanaatindeyiz.

\section{KAYNAKLAR}

1. NIH consensus development conference. Diagnosis, prophylaxis and treatment of osteoporosis. Am J Med 1993; 94: 646-50.

2. Riggs BL, Wahner HW, Melton LJ, et al. Rates of bone loss in the appendicular and axial skeletons of women: Evidence of substantial vertebral bone loss before menopause. J Clin Invest 1986; 77: 1487-91.

3. Zuckerman JD. Hip fracture. N Engl J Med 1996: 334: 1519-25.

4. Celik O, Salci Y, Manisali M, Korkusuz F. The effect of hip rotation on bone mineral density of the proximal femur measured by dual energy $X$-ray absorptiometry. Eklem Hastalik Cerrahisi 2009; 20: 71-7.

5. Christiansen C. Osteoporosis: diagnosis and management today and tomorrow. Bone 1995; 17 : 513-6.

6. Siris ES, Miller PD, Barrett-Connor E, et al. Identification and fracture outcomes of undiagnosed low bone mineral density in postmenopausal women: results from the National Osteoporosis Risk Assessment. JAMA 2001; 286: 2815-22.

7. Schuit $S C$, van der Klift $M$, Weel $A E$, et al. Fracture incidence and association with bone mineral density in elderly men and women: the Rotterdam Study. Bone 2004; 34 : 195-202.

8. WHO. Assesment of osteoporotic fracture risk and its role in screening for postmenopausal osteoporosis. WHO Tecnical Report Series, Geneva, 1994.

9. Hallberg I, Rosenqvist AM, Kartous L, Lofman O, Wahlstrom, Toss G. Health-related guality of life after osteoporotic fractures. Osteoporos Int 2004; 15: 834-41.

10. Küçükardalı Y, Solmazgül E, Kaplan $M$, ve ark. Huzurevinde yaşayan yaşlı popülasyonda osteoporoz taraması. Turkish Journal of Geriatrics 2006; 9: 25-9.

11. Erkin G, Akınbingöl M, Gülşen ED ve ark. Osteoporoz ünitemizde kemik mineral yoğunluğu ölçümü yapılmış olan geriatrik olguların özellikleri. Turkish Journal of Geriatrics 2004; 7: 84-8.

12. Keskin D, Borman P, Eser $F$ ve ark. Yaşlılarda fiziksel aktivite, kemik mineral yoğunluğu ve yaşam kalitesinin değerlendirilmesi. Turkish Journal of Geriatrics 2008; 11: 113-8.

13. Paker N, Buğdaycı D, Dere D ve ark. Relationship between bone density and quality of life in postmenopausal osteoporosis. Turkish Journal of Geriatrics 2012; 15: 19-23.

14. De Laet CE, Van der Klift M, Hofman A. Osteoporosis in men and women: a story about bone mineral density thresholds and hip fracture risk. J Bone Miner Res 2002; 17: 2231-6.

15. Akdemir N, Bilir C, Cinemre H, et al. Relationship of bone densitometry and bone resorption markers with menopausal type and duration. Turk J Rheumatol 2010; 25: 29-33.

16. Kanis JA, Johnell O, Oden A. Ten year probabilities of osteoporotic fractures according to $B M D$ and diagnostic thresholds. Osteoporos Int 2001; 12: 989-95.

17. LaFleur J, McAdam-Marx C, Kirkness C. Clinical risk factors for fracture in postmenopausal osteoporotic women: a review of the recent literature. Ann Pharmacother 2008; 42: 375-86.

18. Brach JS, VanSwearingen JM, FitzGerald SJ, et al. The relationship among physical activity, obesity and physical function in community-dwelling older women. Prev Med 2004; 39: 74-80.

19. Miller PD, Siris ES, Barrett-Connor $E$, et al. Prediction of fracture risk in postmenopausal white women with peripheral bone densitometry: evidence from the National Osteoporosis Risk Assessment. J Bone Miner Res 2002; 17: 2222-30.

20. Cummings $S R$, Karpf $D B$, Harris $F$, et al. Improvement in spine bone density and reduction in risk of vertebral fractures during treatment with antiresorptive drugs. Am J Med 2002; 112: 281-9.

21. Sarkar S, Mitlak BH, Wong M, et al. Relationships between bone mineral density and incident vertebral fracture risk with raloxifene therapy. J Bone Miner Res 2002; 17: 1-10.

22. Kanis JA. Diagnosis of osteoporosis and assessment of fracture risk. Lancet 2002; 359: 1929-36. 
23. Sornay-Rendu E, Munoz F, Garnero $P$, et al. Identification of osteopenic women at high risk of fracture: the OFELY study. J Bone Miner Res 2005; 20: 1813-9.

24. Gülbahar S, El Ö, Altay C ve ark. Postmenapozal osteoporozda vertebra kırık ve yaşam kalitesi arasındaki ilişki. Osteoporoz Dünyasından 2007; 13: 23-7.
25. Friedman AW. Important determinants of bone strength. J Clin Rheumatol 2006; 12: 70-7. 